\title{
KAMU DEĞERİ YÖNETIMI: UYGULAMAYA YÖNELİK BİR YÖNTEM ÖNERİSİ
}

\author{
$\leftrightarrow$
PUBLIC VALUE MANAGEMENT: PROPOSAL OF A METHOD REGARDING APPLICATION

$\ddot{\mathbf{O} z}$

Bu çalışmada Kamu Değeri Yönetimi'nin Kamu Özel Ortaklıkları bağlamında bir uygulama yönteminin sunulması ve bu yöntemin tartışılması amaçlanmıştır. Uygulama yöntemi önerisi özel sektördeki benzer yönetim yaklaşımlarından esinlenerek ortaya konmuştur. Konunun daha iyi anlaşılabilmesi açısından çalışmanın başında kamu değeri yönetimi kavramından özet olarak bahsedilmiştir. Yaklaşımın uygulama konusundaki sıkıntılarına istinaden öncelikle risk ve firsatlar ortaya konmuştur. Bu şekilde olası bir yöntemin uygulanabilirliği değerlendirilmiştir. Yöntemin oluşturulması esnasında yardımcı olabilecek çeşitli özel sektör uygulamalarından da bahsedilmiştir. Gerek bu yöntemlerin uyarlanması gerekse özgün öneriler neticesinde sadece Kamu Özel Ortaklıkları alanında uygulanmak üzere bir yöntem önerisi geliștirilmiştir. Böylece hem konunun geliştirilmesine yönelik kavramsal bir girdi oluşturulması hem de daha sonra yapılacak uygulamaya yönelik çalışmalar için bir katkı sunulması amaçlanmıştır.
\end{abstract}

Anahtar Kelimeler: Kamu Yönetimi, Kamu Değeri, Kamu-Özel Ortakllkları, Yeni Kamu İşletmeciliği, Yönetişim.

\begin{abstract}
In this study, it is aimed to present an application method of Public Value Management in the context of Public Private Partnerships and to discuss this method. The implementation method proposal was put forward inspired by similar management approaches in the private sector. In order to better understand the subject, the concept of public value management was briefly mentioned at the beginning of the study. Risks and opportunities have been set forth primarily regarding the problems of the approach in implementation. In this way, the feasibility of a possible method was evaluated. Various private sector applications that can help during the establishing of the method are also mentioned. As a result of both the adaptation of these methods and the original recommendations, a method proposal has been developed to be applied only in the field of Public Private Partnerships. Thus, it is aimed both to create a conceptual input for the development of the subject and to provide a contribution for the future practice studies.
\end{abstract}

Keywords: Public Administration, Public Value, Public-Private Partnerships, New Public Management, Governance.

\footnotetext{
${ }^{*}$ Bu çalışma, Bursa Uludağ Üniversitesi, Sosyal Bilimler Enstitüsü, Siyaset Bilimi ve Kamu Yönetimi Yüksek Lisans Programı'nda, Fatih GENÇOSMAN tarafından, Prof. Dr. Bekir PARLAK danışmanlığında tamamlanan "Kamu Değeri Yönetimi Bağlamında Kamu-Özel Ortaklıkları” başlıklı yüksek lisans tezinden türetilmiştir.

** ORCID Prof. Dr. Uludağ Üniversitesi Siyaset Bilimi ve Kamu Yönetimi Bölümü, bepar@uludag.edu.tr

*** ORCID Özel Sektör Genel Müdür, fgencosman@yahoo.com
} 


\section{EXTENDED ABSTRACT}

\section{Introduction and Research Questions \& Purpose:}

Public value management is a value-based public administration approach introduced by Mark $\mathrm{H}$. Moore towards the end of the 2000s. It has taken its place among the candidates of the future public administration approach with its close relationship to the network governance concept, its theoretical position at an equal distance to traditional public administration and New Public Management. Public value management is being explored with increasing interest, and the literature on this topic remains alive. In this study, public-private partnerships models, on which little work has been done so far, is examined in the context of public value management. For this purpose, it is aimed to present an application method of Public Value Management in the context of Public Private Partnerships and to discuss this method. The application method proposal is inspired by similar management approaches in the private sector. In order to understand the subject better, the concept of public value management was briefly mentioned at the beginning of the study.

\section{Literature Review:}

When the literature on the concepts of public value and public private partnerships was searched, two sources stand out. The first and most important of these is the publication "Creating public value through private / public partnerships" written in 2005 by Mark H. Moore, the theorist of the concept of public value. In this paper, Moore attempted to explain how public value plays a role in public private partnerships, using an example he also handles in his book. Moore also pointed out that the private sector, which uses public authority under certain conditions, should protect public value. The other one is "Public Values and Integrity in PublicPrivate Partnerships", owned by Anne-Marie Reynaers and published in 2010. Since the concept of public values is different from public value, it takes an indirect approach to the issue.

\section{Methodology:}

Although public value management is an interesting approach, its difficulties in practical implementation prevented it from being widely used. Especially how it coincides with public private partnership models is a factor that makes it difficult to work because the problems about the partnerships themselves have not been solved yet. For this reason, the main problems regarding the implementation of public value management in public private partnership models were determined and their explanations were given as items in the study. However, besides these basic problems, there are also opportunities to make possible an application method proposal. These opportunities were included in the study and explained in detail under subheadings. Analyzing the problems and opportunities has led us to a method proposal.

The proposed method consists of three main headings: The first heading is "Public Value Management Transformation in the Public Side of the Partnership". Under this heading, it is explained with a brief approach what kind of change and transformation should take place within the framework of Public Value Management principles. Secondly, there exist the title "A New Type of Relationship Between Public and Private Sector: Strategic Partnership". It has been suggested that the type of relationship in the form of strategic partnership, which has examples in the private sector before, should be established between the public and private sectors. Since it will have a unique structure, the features of this type of relationship are also briefly included. The last title has been determined as "Public Value Based Performance System". Under this heading, a performance system that can be applied within the public-private partnership model is explained. This performance system will have a mechanism to measure the performance of private companies doing business with the public and the public private partnership business models to be established in terms of public value.

\section{Results and Conclusions:}

As a result, an application method on Public Value Management and public-private partnerships model has been proposed and discussed in various aspects in this study. This method has been created by making use of other successful methods that have similar models in the private sector. For this reason, the method defined is considered to be applicable. Thus, it has been tried to show that it is possible to implement in a new field for Public Value Management and, if implemented, it can be an effective method to generate public value. At the same time, it is aimed both to create a conceptual input for the development of the subject and to provide a contribution for future studies. 


\section{GİRiş}

Kamu değeri yönetimi (KDY), ağ yönetişimi kavramı ile sıkı ilişkisi, geleneksel kamu yönetimi ve Yeni Kamu İşletmeciliği’ ne eşit mesafede kuramsal konumu ile geleceğin kamu yönetimi yaklaşımı adayları arasında gösterilmektedir. $\mathrm{Bu}$ konuda araştırmalar devam etmekte, yazın canlılı̆̆ını sürdürmektedir. Ancak devam eden araştırmalara rağmen kavramın uygulama tarafinda gelişmesi aynı hızda olmamıştır. Uygulamaya yönelik çalışmalar daha çok deneysel düzeyde pilot çalışmalarla sınırlı kalmış, kamu idarelerinin benimseyebileceği yaygın bir kullanım alanı henüz oluşmamıştır.

Kamu özel ortaklıkları (KÖO) kökeni daha eskilere dayanmakla birlikte Yeni Kamu İşletmeciliği reformları ile popülaritesi artan dolayısıyla bu reformlarla özdeşleşmiş kavramlardan birisidir. Son yıllarda gerek finansman kaynaklarının çeşitlendirilmesi gerekse özel sektörün verimliliğinden istifade etmek gibi temel saiklerle ön plana çıkan uygulamalardan biri olmuştur ve konu hakkında yazın canlılığını korumaktadır.

Bu çalışma kamu değerinin uygulamaya yönelik eksiklerine katkı sunmak üzere hazırlanmıştır. $\mathrm{Bu}$ amaçla yukarıda yer verilen KÖO modeli uygulama alanı olarak belirlenmiştir.

Çalışmada kamu değeri yaklaşımı prensipleri temel alınarak KÖO özelinde bir uygulama yöntemi önerisi sunulmuştur. Bunu sunarken bir taraftan benzer özel sektör uygulamalarından esinlenilmiş bir taraftan da bu iki kavramı örtüştürmenin zorlukları gösterilmiştir. Çünkü kamu değeri yaklaşımı KÖO'lara daha farklı bir perspektiften bakmaktadır. Bu açıdan en önemli nokta kurulacak ortaklık yapısında kamu değerinin nasıl sağlanabileceği üzerinedir. Ancak özel sektörün kamu ile yapılacak bir ortaklıktan en büyük beklentisi ve motivasyonu elde edeceği kâr miktarıdır. Bu yüzden kamu değeri açısından bakıldığında KÖO'ları değer temelli bir çerçeveye oturtmak kolay gözükmemektedir.

Kamu değeri ve kamu özel ortaklıkları kavramları çok da yeni kavramlar olmamasına karşın bunların birlikte kullanımına pek sık rastlanılmamaktadır. Konuyla ilgili literatür araştırıldığında iki kaynak göze çarpmaktadır: Bunlardan en önemlisi kamu değeri kavramının teorisyeni olan Mark H. Moore'un 2005 yılında kaleme aldığı "Creating public value through private/public partnerships" isimli yayındır. Bu yayında Moore kitabında da ele aldığ 1 bir örnek üzerinden kamu değerinin KÖO üzerinde nasıl bir role sahip olduğunu anlatmaya çalışmıştır. Moore ayrıca kamu otoritesini belli şartlar altında kullanan özel sektörün kamu değerini gözetmesi gerektiğine işaret etmiştir (Moore, 2005). Bu yayınla ilk defa olarak Moore kamu değeri kavramını KÖO bağlamında incelemiş ve literatüre bu konu hakkında bir çalışma sunmuştur. Bir diğer kaynak ise Anne-Marie Reynaerse ait olan ve 2010 yılında yayınlanan "Public Values And Integrity In Public-Private Partnerships" isimli yayındır (Reynaers, 2010). Bu yayında aslen kamu değeri ile karıştırılan fakat farklı anlamlara sahip kamu değerleri kavramı kullanılmıştır. Bu yüzden içerik olarak konuya dolaylı bir yaklaşım sergilemektedir. Bu yayında kamu özel ortaklığı yapısı tarafından sağlanan hizmetlerin kamu yararı gözetecek şekilde değerlendirilmesi ele alınmıştır.

\section{KAMU DEĞERİ YÖNETIMİ-KAVRAMSAL ÇERÇEVE}

Devlet kurumu gerek kamu hizmetleri gerek yasama işlemleri ve gerekse diğer yaptığı tüm işlemler nedeniyle çeşitli kaynaklar kullanır ve bunların sonucunda bir değer üretir. Moore'a göre kamu kaynakları özel sektördekine benzer şekilde üretilen bu değerin artırılması için kullanılmalıdır. Ancak bu değer özel sektördeki finansal çıktıların çok daha ötesinde bir anlama sahip olup vatandaşların en fazla neye değer verdiği, en fazla neyden fayda sağladığıyla ilgilidir (Williams \& Shearer, 2011:1). Açık bir tanım yapmasa da Moore kamu değerini neyin değerli olduğunu anlamamıza yardımcı olan, kamu tarafından üretilen değer ile vatandaşlar tarafından algılanan değer arasındaki ilişkiyi kurmamamızı sağlayan bir çerçeve olarak görür (Williams \& Shearer, 2011:6). Demokrasilerde bu değer halk tarafından, vatandaşların tercihleri, politikacıların kararları gibi etkenler sonucu çeşitli 
vasitalar yoluyla belirlenir. Kamu tarafından üretilen değer, vatandaşların kamuya vermeyi kabul ettiği yetki ve kaynaklar ile elde ettikleri fayda arasındaki farkı yansıtmaktadır. Hatta hükümetin meşruluğu büyük ölçüde ne kadar değer yaratabildiği ile ilgilidir. Kamu değeri kaynakların doğru şekilde tahsis edilebilmesi ve doğru kararların verilebilmesi için kamu kurumları ve politikaları için bir ölçüt görevi görür (Kelly vd., 2002:3).

$\mathrm{Bu}$ açıklamalar 1şı̆̆ında kamu değeri yaklaşımının en temel önermeleri özetle şu şekilde verilebilir:

1. Kamu sektörü özel sektörden farklıdır. Kamunun kendisine has yapısı vardır ve özel sektörde geçerli olan ekonomik faydacı yaklaşımlar kamu sektörü için yeterli değildir (Moore, 1995).

2. Devlet kurumları verdikleri hizmetler, yasama ve diğer işlemleri nedeniyle bir değer üretirler. Ancak bu değer vatandaşların algıları, tercihleri, kazanımları yoluyla tanımlanır (Kelly vd., 2002).

3. Kamu yöneticilerinin temel görevi kamu değerini araştırmak, ne olduğunu anlamaya çalışmak ve özellikle siyasa yapıcılara kamu değerini açıklamaktır (Moore, 1995).

4. Kamu değeri siyasa karar vericileri, kamu yöneticileri ve ilgili tüm paydaşların katılımı ile gerçekleşecek diyalog ve müzakereler ile belirlenmelidir (Stoker, 2006).

5. Kamu değeri sadece çıktılarla üretilmez. Aynı zamanda güven ve adalet duygusu oluşturabilecek süreçler yoluyla da üretilebilir (O'Flynn, 2007).

6. Kamu değerini artırmak veya maksimize etmek hükümetlerin önemli öncelikleri arasında olmalıdır. Politika ve stratejilere bu ölçüt yön vermelidir (Kelly vd., 2002).

7. Kamu değeri hükümet işlemlerine meşruiyet sağlamanın bir yoludur. Bunun için ilgili tüm paydaşların da katılımı sağlanmalıdır (Stoker, 2006).

Yukarıda sayılan bu açıklamalar kamu değerinin ne olduğunu anlamamıza yardımcı olurken bu yaklaşımın nasıl tatbik edileceği konusunda pratik bir yöntem sunmamaktadır. Moore kitabında detaylı bir uygulama rehberi vermemiş fakat uygulama ile ilgili ipuçlarını stratejik üçgen (şekil 1) kavramıyla açıklamıştır. Buna göre stratejik üçgen kamu değerinin sağlanabilmesi için ayrı fakat birbirine bağımlı üç süreçten oluşur: Birincisi kuruluşun genel misyonunu veya amacını bildirir. İkincisi toplumunun kuruma bağ lılığını sürdürecek destek ve meşruiyet kaynaklarını sunar. Üçüncüsü belirlenen hedeflere ulaşmak için kurumun nasıl organize olacağı ve işletileceğini açıklar (Moore, 1995:71).

Moore, Benington ile birlikte kaleme aldığ "Public Value: Theory and Practice" isimli kitabında stratejik üçgeni aşağıdaki şekilde tanımlamışlardır (Horner \& Hutton, 2011:4):

(1) Kamu değerinin tanımlanması: Stratejik hedeflerin, kamu değeri çıktılarının belirlenmesi ve açıklanmasıdır.

(2) Yetkilendirme: Kamu değeri çıktılarının elde edilmesi için yetki çevresinin oluşturulması gereklidir. Stratejik eylemler için desteği gereken kamu, özel ve diğer sektörlere ait paydaşlar ile sürdürülebilir bir koalisyonun oluşturulmasıdır.

(3) Operasyonel kapasitenin teşekkülü: İstenilen kamu değeri çıktılarının elde edilebilmesi için hem kurum içi hem kurum dışı operasyonel kaynakların (finans, teknoloji, uzmanlıklar, yetenekler vs.) seferber edilmesidir. 


\section{Şekil 1: Moore'un Stratejik Üçgeni}

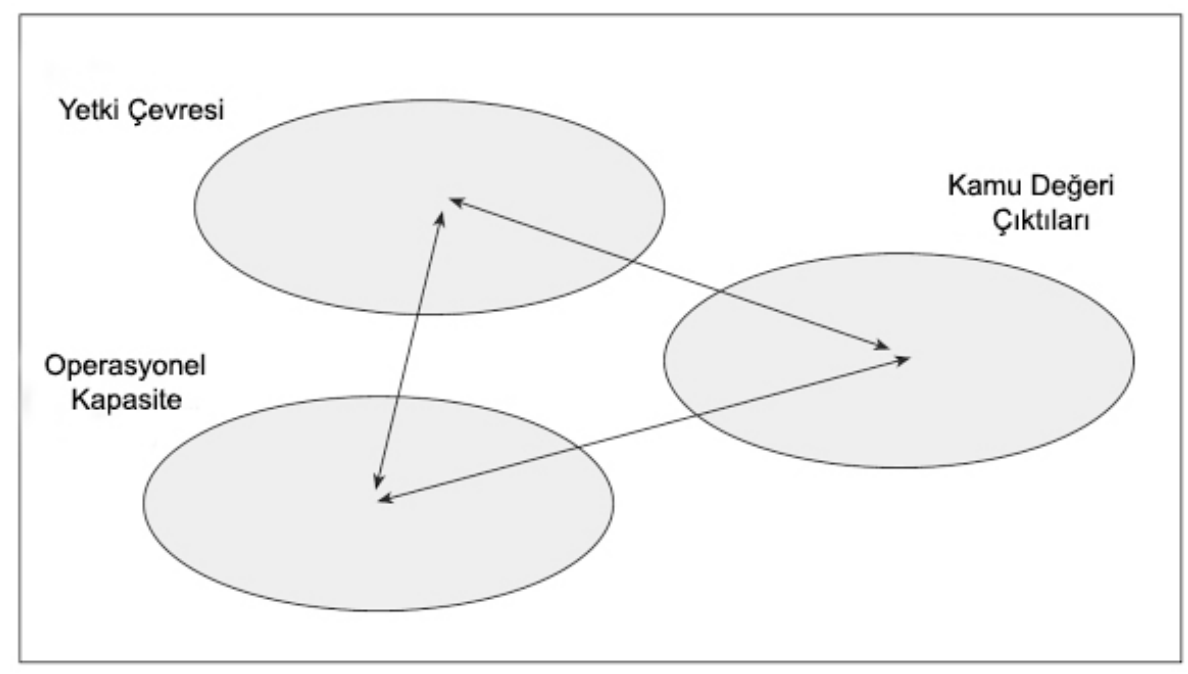

Kaynak:(Benington \& Moore, 2011:5)

Moore stratejik üçgeni kamu yöneticileri için düşünmüş ve kamu değeri bağlamında strateji geliştirme işlevini de kamu yöneticilerine vermiştir. Buna göre bir kamu yöneticisi strateji geliştirirken üçgendeki bu elemanları aşağıdaki kriterlere göre değerlendirmeli ve tutarlı bir ölçeklendirme yapmalıdır. Birincisi strateji kurumun ilgili çevresi (politikacılar, vatandaşlar vs.) için önemli ölçüde bir değer sağlamalıdır. İkincisi yasal ve politik olarak sürdürülebilir olmalıdır. Yani yetki çevresinden kaynak almaya devam etmeli, işlemler politik olarak onay görmelidir. Üçüncüsü operasyonel ve yönetimsel olarak yapılabilir olmalıdır. Kurumun kaynaklarını veya yetki çevresini aşan bir strateji olmamalıdır (Moore, 1995:71).

Stratejik üçgenin elemanları bir kurumda kamu değeri oluşturmak için çok önemli görülmüştür. Çünkü yaklaşımın uygulayıcısı olan kamu yöneticisinin nasıl hareket etmesi gerektiğini göstermektedir. Geleneksel yaklaşımda kamu yöneticisinin yetki ve görevlerine yönelik ayrıntılı talimatlar ve yönergeler mevcuttur ve hareket alanı net bir şekilde belirlenmiştir. Yeni Kamu İşletmeciliği'nde (YKİ) kamu yöneticisinin hareket alanı biraz daha artmış ancak elde etmesi gereken çıktılarla operasyonel olarak sınırlanmıştır. Kamu değeri yaklaşımında ise kamu yöneticisi vizyonu, hayal gücü, yetenekleri doğrultusunda daha serbest bırakılmıştır. Ancak bu serbestliğin belirsizlik yaratma ihtimali ve suistimale açık oluşu nedeniyle bir anlamda stratejik üçgen ile sınırları çizilmektedir. Sonuçta kamu yöneticisi tamamen serbest bırakılmamıştır ve yapacağı tüm işler için yetki çevresinden onay almak zorundadır. Kamu yöneticisi bir taraftan talimat ve yönergelerin yerine getirilmesi için kurumun içine bakacak, diğer taraftan daha fazla değer sağlayacak eylemler için kurumun dişına bakacaktır. Yetki sınırlarını aşan eylemler için ise politikacıları ikna etmesi gerekecektir.

Kamu yöneticisinin yetki çevresine giderken ve onay isterken önemli bir dengeyi göz önünde bulundurması gereklidir. Eğer yetki istediği eylemler kamu değeri yaratan ama operasyonel olarak yapılabilir değilse politik destek sağlasa bile sonuç başarısız olacaktır. Tam tersine çok değer katacak bir eylem için politik destek sağlayamaz ise operasyonel olarak yapılabilir olsa bile sonuç yine başarısız olacaktır. Son olarak kamu değeri sağlamayan bir eylem için politik destek sağlasa ve eylem operasyonel olarak yapılabilir olsa da strateji yine yürümeyecektir. Değer katmayan eylem paydaşlar tarafından destek görmeyecek ve kaynaklar israf edilmiş olacaktır (Moore, 1995:74). Bu yüzden stratejik üçgen bir açıdan üç ayaklı sacayağa benzetilebilir. Kamu yöneticisi kamu değeri sağlayacak stratejilerini her bir ayağı dengeli oturtacak şekilde planlamalı ve yönetmelidir.

Kamu yöneticisi yaklaşımın önemli faktörlerinden birisi iken diğer önemli faktörlerden birisi de vatandaşlardır. Belki de kamu değeri yaklaşımını farklı kılan en önemli özelliklerden birisi 
vatandaşı pasif bir nesne yerine kamu siyasalarının oluşturulması ve uygulanması sürecinde etkin bir özne olarak gören yaklaşımıdır (Karkın, 2012:370). Geleneksel kamu yönetiminde vatandaşın katılımı oy verme, siyasi partiye katılma gibi temsili demokrasi araçlarıyla sınırlandırılmıştır. YKİ ise vatandaşı daha çok bir müşteri olarak görmekte, katılım şekli danışma ile sınırlı kalmaktadır (Köseoğlu \& Sobacı, 2014:441). Hâlbuki kamu değeri yaklaşımında vatandaş katılımı siyasa yapım sürecine de nüfuz etmekte, temsili demokrasinin bir adım ötesine geçilmektedir. Yaklaşımın temel referans noktası olan kamu değerinin ne olduğu ancak kamu yöneticileri ve kilit paydaşların müzakeresi sonucu kolektif bir şekilde anlaşılabilir. Kamu değerinin çok çeşitli sosyal bağlamlarda üretilmesi, vatandaşların istek ve algısına dayanması ve toplumsal tecrübeden çıkarılması böyle bir müzakereyi zorunlu kılar (Köseoğlu \& Tuncer, 2014:154). Müzakere ve işbirliği süreci atanmış memur, seçilmiş politikacı ve vatandaş arasında olabileceği gibi topluma yön veren tüm aktörlerle de (özel sektör kuruluşları, gönüllü kuruluşlar, meslek odaları, kanaat önderleri vs.) yürüyebilir. Bu durumda kamu değerinin anlaşılması bir ölçüde tüm kilit paydaşların karmaşık ağ ilişkileri içerisinde müzakere sürecine katılmasıyla mümkün olur. Kamu değeri bu yönüyle ağ yönetişimi kavramıyla en fazla uyum sağlayan yaklaşımdır ve diğer yaklaşımlara kıyasla demokrasi ve katılımı çok daha büyük ölçüde desteklemektedir. Stoker kamu değerinin bu yönünü "Ă̆ yönetişimi için yeni bir anlatı" başlıklı yazısında ele almış, yaklaşımın en güçlü yanının insanları katılıma motive etmekte yattı̆̆ını söylemiştir (Stoker, 2006:5).

Katılımın sağlanması, işbirliği ve müzakere yoluyla kamu değerinin ne olduğu, hangi eylemlerin değer üreteceği, organizasyonun mevcut değer üretme kapasitesi gibi konular somutlaşmaya başlar. Kamu değerinin anlaşılması ise organizasyona yön verecek stratejilerin belirlenmesini, değer odaklı bir performans yönetimini mümkün kılar ve bu yolla yaklaşım teorik düzeyden pratik düzeye geçebilir. Bu yüzden kamu değerinin anlaşılması uygulama yönündeki ilk adım iken ikinci en önemli adım strateji ve eylemlerin kamu değerine yönelik olarak planlanması ve uygulanmasıdır. Kamu değerinin çeşitli araçlar yoluyla ölçülmesi uygulamanın üçüncü adımını oluşturmaktadır. Bu yolla hangi eylemlerin gerçekten kamu değerini artırdığı, hangi eylemlerin ise değer üretmediği anlaşılır olacaktır (Moore, 1995; Kelly vd., 2002). Nitekim yapılan ilk uygulama örneklerinde benzer şekilde kamu değerini anlama ve değerlendirme çalışmaları göze çarpmaktadır.

\section{KAMU ÖZEL ORTAKLIKLARI MODELLERİ ICÇIN BİR UYGULAMA ÖNERISII: KAMU DEĞERI TEMELLI ORTAKLIK MODELI}

$\mathrm{Bu}$ çalışmanın amacı bundan sonra kamu değeri yönetimi (KDY) olarak adlandıracağımız bu yeni yaklaşıma uygulama bağlamında bir öneri getirmektir. Böylece uygulama azlığı nedeniyle pek fazla yaygınlaşma imkânı bulmayan bu yaklaşıma önemli bir kavramsal girdi sağlanması da mümkün olabilecektir. Bu sebeple böyle bir uygulama önerisi için KÖO modeli seçilmiştir.

Giriş kısmında da belirtildiği üzere KÖO modellerine kamu değeri temelli bir yaklaşımın uygulanması çeşitli sorunları beraberinde getirecektir. Bu yüzden öncelikle temel sorunlar irdelenecek sonrasında ise firsatlar ortaya konacaktır. Son olarak riskler ve fırsatlar ışığında uygulama önerisine yer verilecektir.

\subsection{Kamu Özel Ortaklıkları Modellerinde Kamu Değeri Yönetimi Uygulamasına Yönelik Temel Sorunlar}

\subsubsection{Kamu Değeri ile Özel Dĕgerin Uyuşmazlı̆̆ı}

KÖO modellerinin tümünde özel sektörün bu ortaklığa katılımında temel motivasyon kâr elde etme beklentisidir. Kâr elde etme saikiyle katılım gösteren özel sektör firmaları ortaklığın kamu değeri üretip üretmediği ile pek ilgilenmemektedir. Firmalar için önemli olan finansal niceliğe sahip olan özel değerdir (Kivleniece \& Quelin, 2012:11-12). 
Firmalar iş yaparken çeşitli kaynakları kullanır ve serbest piyasa fiyat mekanizması aracılığı ile bir değer üretirler. Üretilen bu değeri ölçebilmek için çeşitli yöntemler kullanırlar ve bu açıdan kamu değerinden farklı şekilde özel değer ölçülebilir özelliğe sahiptir (Kelly vd., 2002:8). En eski ve yaygın bilinen tanım özel değerin firmanın hisse değeri olduğunu söyler. Günümüz modern yönetim yaklaşımlarında müşterinin para ödemeye razı olduğu mal ve hizmet özelliklerinin özel değeri tanımladığı varsayılır.

Kamu değeri ise özel değerden oldukça farklı bir kavramdır. Aslında hizmeti veren kamu adına bir özel sektör firması olsa bile kamu değeri üretmektedir. Ancak önemli olan firmanın bu değeri artıracak hedef ve politikalara sahip olma zorunluluğudur. Özel sektör vereceği hizmet ile bir kamu değeri üretse bile bu değeri artıracak bir çaba sergilemesine ihtiyaç bulunmamaktadır. Firmaların bu ortaklıkta artırmaya çalıştıkları tek değer özel değerdir. Kamu değeri ile özel değer farklı niteliklere sahip oldukları için değerlerin uyuşmazlığı KÖO modellerinde bir sorun olarak ortaya çıkmaktadır.

\subsubsection{Kamu Özel Ortaklıkları Modellerinde Kamu Değerinin Bir Öncelik Oluşturmaması}

KÖO modellerinin yaygınlaşmasını sağlayan faktörler incelendiğinde finansman kaynaklarının çeşitlendirilmesi, özel sektörün verimlilik tecrübelerinden istifade etmek gibi mali etkenler öne çıkmaktadır (Güzelsarı, 2009). Mevcut modellerin kurulmasında kamu değeri bir öncelik olarak yer almamaktadır. Normatif olarak devletin özel sektör ile kurulacak ortaklıkta kamu değerini maksimize etmek istemesi beklenebilir. Ancak mevcut KÖO uygulamalarını teşvik eden nedenlerden en önemlisi finansman olduğu için firmaların bu ortaklığa cezbedilmesi daha öncelikli bir konu haline gelmektedir.

\subsubsection{Kamu Değeri Yönetimi Uygulamalarının Azlı̆̆ı ve Tecrübe Eksikliği}

KDY'nin ortaya çıkışı üzerinden 20 yıldan fazla süre geçmesine rağmen YKİ reformları benzeri yaygın bir uygulama alanı oluşmamıştır. Bugüne kadar yapılan tüm uygulamalar dar ölçekli ve biraz da test amaçlı pilot uygulamalardan oluşmaktadır. Pilot uygulamaların büyük çoğunluğu ise sosyal çıktılara sahip devlet kurumlarında (BBC, Kraliyet Operası vb.) gerçekleştirilmiştir (Horner vd., 2007). Bu yüzden kamu değeri temelli bir yönetim anlayışının daha kompleks hizmet birimlerinde tesisine ilişkin bilgi ve tecrübe eksikliği bulunmaktadır.

\subsubsection{Kamu Özel Ortaklıklarının Karmaşık Yapısı}

KDY'nin kamu özel sektör arasındaki ortaklıklarda uygulanmasını zorlaştıran bir başka konu ortaklığın karmaşık bir hukuki yapıya sahip olmasıdır. Ayrıca çok çeşitli ortaklık modeli olması da karmaşıklığı artırmaktadır. KÖO’ler finansmanın sağlanma şekli, risk paylaşımı, ortaklığın süresi, hizmetin sunulma yöntemi gibi parametrelerin belirlediği çeşitli modellere sahiptir. Ülkemizin de içinde olduğu bazı ülkelerde hem model hem de sektör bazında hukuki düzenlemeler yapıldığı için KÖO mevzuatı karmaşık bir yapıya sahiptir. AB komisyonu 2004 yılında mevzuatın netleştirilmesi ve kavramsal karmaşanın azalmasına yönelik "Yeşil Kitap" yayınlamıştır. Şimdilik AB düzeyinde KÖO’ları düzenleyen bir mevzuat ise bulunmamaktadır (Uz, 2007:1171).

\subsection{Kamu Özel Ortaklıkları Modellerinde Kamu Değeri Yönetimi Uygulamasına Yönelik Firsatlar}

\subsection{1. Özel Sektörün Değer Temelli Yönetim Tecrübesi}

KDY'yi diğer kamu yönetimi yaklaşımlarından ayıran en önemli noktalardan birisi değer temelli bir yapıya sahip olmasıdır. Bu konu kamu yönetimi disiplinleri için oldukça yenidir. Elbette hemen tüm 
kamu yönetimi yaklaşımları içinde kamu yararı veya kamusal fayda kavramı bulunmaktadır. Fakat KDY bölümünde açıklandığı üzere kamu değeri bunlardan daha farklı bir kavramdır. Ayrıca kamusal fayda veya kamu yararı diğer yaklaşımlarda stratejilerin belirlenmesini değil, hizmetin veriliş nedenlerini açıklayan kavramlar olarak öne çıkmaktadır (Köseoğlu \& Sobac1, 2014).

Kamu yönetimi yaklaşımları için değer temelli yönetim yaklaşımı yeni ve farklı olsa da özel sektör firmaları için aynı şeyi söylemek mümkün değildir. Özel sektörde yıllardır değer temelli yönetim anlayışına sahip olan ve uygulayan firmalar mevcuttur. Özellikle son dönemlerde modern yönetim felsefelerini (Toplam Kalite Yönetimi, Yalın Üretim vb.) uygulayan firmaların artmasıyla özel sektörde değer temelli yönetim yaklaşımları yaygınlaşmaya başlamıştır. Bir taraftan bu yaklaşımlar daha fazla kabul görürken bir taraftan finansal değerin anlamı da genişlemeye başlamıştır. Günümüzde birçok tanınmış büyük ölçekli firma için çevreye saygı, işçi ve iş güvenliği, ürün kalitesi gibi kavramlar finansal getirilerin önüne geçmeye başlamıştır (Martin \& Petty, 2001), (Brandenburger \& Stuart 1996).

Netice olarak özel sektörde özellikle son yıllarda hâkim konuma gelen modern yönetim tekniklerinin değer odaklı yaklaşımları özel sektörün bu konudaki tecrübesini artırmıştır. Bu sayede yine değer odaklı bir yaklaşım olan KDY'nin özel sektör ile birlikte uygulanabilirliği bu tecrübe sayesinde artmaktadır. Bu sayede kamu ile özel sektörün yapacağı ortaklılarda değer odaklı bir yönetim tarzı benimsemiş firmalarla KDY yaklaşımı daha kolay şekilde hayata geçirilebilecektir.

\subsubsection{Uygulama Kapsamının Dar olması}

KÖO modellerine yönelik kamu değeri temelli bir uygulama büyük bir dönüşüm hareketi gerektirmeyecektir. Çünkü kamu tarafında özellikle ortaklıkla ilgili koordinasyonu sürdüren ve yeni projelerin fizibilite çalışmalarını yapan birimler doğrudan etkilenecektir. Böylece uygulama yapılacak kapsam sınırlı olacak, daha önceki pilot çalışmalar benzeri uygulamalar mümkün olabilecektir (Horner vd., 2007).

\subsection{3. Özel Sektörün Esnek Yapıst}

Özel sektörün kamu kesimine karşı önemli avantajlarından bir tanesi de değişime karşı çok daha hızlı tepki verebilmesi ve uyum sağlayabilmesidir. Kamu değeri temelli bir dönüşümde özel sektöre yeni ve farklı sorumluluklar düşse de özel sektör bu yeni yapıya kamu kesimine göre daha kolay adapte olabilecek esnekliğe sahiptir. Her ne kadar kamu kesimi daha çok denetleyen, takip eden konumunda olsa da böyle bir dönüşümde özel sektörden daha fazla zorlanacaktır. Bu yüzden özel sektörün değişime daha hızlı adapte olmasını sağlayan esnek yapısı KDY bağlamındaki bir dönüşüm için avantaj olacaktır. Değişimde zorlanan ve daha katı yapıya sahip olan kamu kesiminin böyle bir dönüşümde daha çok kontrol eden, yaptıran konumda olması da KDY bağlamındaki bir dönüşüm için firsat oluşturmaktadır (Devos \& Bouckenooghe, 2006).

\section{UYGULAMAYA YÖNELİK YÖNTEM ÖNERİSI}

Yukarıda açıklanan riskler ve firsatlar uygulamaya yönelik bir yöntem önerisi için 1şık tutmaktadır. $\mathrm{Bu}$ bağlamda sunulacak olan yöntemin burada sayılan riskleri gidermesi ve firsatlardan yararlanmas1 öngörülmektedir. Bunu sağlayabilmek için yöntem önerisi üç başlık altında verilmiştir. İlk başlıkta ortaklığın kamu tarafında dönüşümü ele alınmıştır. Bu başlık ile KDY alanında uygulama azlığı risk faktörüne rağmen kapsamın daha dar tutulması nedeniyle bu faktörün risk oluşturmayacağ değerlendirilmektedir. Diğer başlık olan Stratejik Ortaklık sayesinde ise kamu değeri KÖO'lar için öncelikli bir değer haline gelerek değerlerin uyuşmaması riski giderilecektir. Son başlık olan 
performans sistemi sayesinde KÖO’ların karmaşık yapısına rağmen kamu değerinin öncelik olarak ele alınacağı bir sistem ortaya konmuş olacaktır.

Aşağıda bu başlıkların detaylarına yer verilmiştir:

\subsection{Ortaklığın Kamu Tarafında Kamu Değeri Yönetimi Dönüşümü}

Kamu değeri temelli bir KÖO yapısı için ilk adım kamu kesiminde KDY prensipleri doğrultusunda bir dönüşümün gerçekleşmesidir. $\mathrm{Bu}$ dönüşümün ilk halkası projenin hedef ve vizyonunun belirlendiği fizibilite ve kabul aşamasıdır. Bu dönemde projenin hangi amaçlarla kabul edilmesi gerektiği ve yapılabilirliği ortaya konmaktadır. Dönüşümün ikinci halkası ise yürütme aşamasında olacaktır. Projenin yürütme aşamasında koordinasyonu sağlayan birimi etkileyecektir.

Kamu tarafında en radikal değişiklik KÖO’ların kurulma amacının kamu değerini artıracak bir amaca yönelmesi olacaktır (Moore, 2005). Buna yönelik olarak kamu değeri göstergelerinin henüz proje başında belirlenmesi gerekecektir. Bu bağlamda KÖO kapsamındaki bir projenin fizibilite aşamasında yapılacak işin kamu değerini nasıl etkileyeceği, kamu değeri olarak hangi göstergelerin etkileneceği, bu göstergelerde olumlu olumsuz hangi değişikliklerin meydana geleceği ve netice olarak yapılacak işin kamu değeri üretip üretmediği mutlaka yer almalıdır.

KÖO projelerinin yürütme aşamasında ise koordinasyonu sağlayan kamu biriminde KDY bağlamında bir dönüşüm gerekecektir. KDY bağlamındaki değişiklik sonucu koordinasyonu sağlayacak kamu birimine yeni görevler verilecektir. Buna göre bu birim projede belirlenmiş olan kamu değeri göstergelerini takip edecek, firmanın verilen hedeflere ve belirlenen standartlara göre çalışıp çalışmadığını denetleyecektir. Bunun yanı sıra firmanın kamu değeri üretmedeki kapasitesini artırmak için hem danışmanlık yapacak hem de firmanın sürekli gelişim faaliyetlerini yakından takip edecektir (Yang, 2016). Yeni yapıda kamu koordinasyon birimi özel sektörü hem denetleyen hem de gelişimi için rehberlik eden bir özelliğe kavuşacaktır. Tabi bunun için de ilgili kamu görevlilerinin görev, yetki ve sorumluluklarının buna uygun olarak yeniden tanımlanması ve gerekli eğitimlerin verilmesi gerekecektir.

\subsection{Kamu ile Özel Sektör Arasında Yeni Bir İlişki Türü: Stratejik Ortaklık}

Ülkemizdeki KÖO projeleri ve uygulamaları incelendiğinde kamu kesiminin özel sektör firmalarına genellikle iş odaklı bir ortaklık önerdiği görülmektedir. Buna göre yapılacak işin çerçevesi, finansman modeli, kamunun yükümlülükleri baştan belirlenmekte, özel sektör kendi alanı ile ilgili çalışmalarda serbest bırakılmaktadır. Kamu ise kendi yükümlülüklerine odaklanmaktadır.

KDY bağlamında bir ortaklık için özel sektörde örnekleri bulunan değer temelli yönetim modellerine benzer bir ilişki türü gerekmektedir. Bu tür bir ilişki için özel sektör uygulamaları incelendiğinde değer temelli yönetim felsefelerinden biri olan yalın üretim felsefesi ön plana çıkmaktadır. Çünkü özellikle otomotiv sanayinde sıklıkla kullanılan yalın tedarik zinciri ilişkileri referans alınabilecek bir ortaklık türü olarak dikkat çekmektedir. Bu ortaklık türünde üretici firma tedarikçileri ile çok daha sıkı ilişkiler geliştirmekte ve klasik tedarikçi ilişkilerinin ötesine geçilmektedir. Mevcut KÖO’lar ise daha çok klasik üretici tedarikçi anlayışına göre kurulmaktadır. Yalın tedarik zinciri klasik anlayıştan daha farklı özelliklere sahiptir ve firmalar arasında kader ortaklığ temelinde bir ortaklık tesis edilmesini istemektedir (Rivera vd., 2007: 241-268). Bu yönüyle değer temelli bir yönetim modelini desteklemeye uygun bir altyapı sunmaktadır. Referans alınan bu ilişkinin adı bu çalışmada stratejik ortaklık olarak tanımlanmıştır.

Stratejik ortaklıkla kamu kesimi özel sektör firmaları ile sadece belli bir işin yapılması, belli bir projenin tamamlanması için ortaklık kurmayacaktır. Ortaklık kurulan firma ile karşılıklı çıkarlara dayanan uzun vadeli stratejik bir ilişki kurulacaktır (Liker, 2004). Bu ilişki türünde amaç özel sektör 
firmalarına uzun süreli olarak iş yapma motivasyonu sağlamak, bu beklenti ile özel sektörün hemen hemen tüm iş yapım sürecine müdahil olmaktır.

Stratejik ortalıkta amaç kamunun ortaya koyduğu değerlere uygun hareket eden firmalarla sürekli işbirliği yapmak ve firmaları bu değerlere uyma konusunda motive etmektir. Kamu ile stratejik ortaklık kuran firmalarda elbette kâr beklentisi de olacaktır. Ancak uzun vadeli bir işbirliğinin getirisi alınan bir veya birkaç işin getirisinden çok daha yüksek olacaktır. Bu yüzden temelinde kamu değeri olan bir ortaklık ilişkisi sonucunda özel sektör firmalarının da amaç ve hedefleri bu doğrultuda değişiklik gösterecektir. Çok daha uzun vadeli bir getiri sağlamanın yolu kamunun belirlediği değerleri ön plana almak, bu değerleri benimsemekten geçecektir. Bu sayede özel sektör firmaları sadece bir iş yapımında bu değerleri temel almayacak, kamu ile stratejik ortaklık ilişkisi sürdügü müddetçe bu değerlere uygun davranacaktır. Hatta firma yönetim ve iş modellerini bu değerlerin sağlanmasına yönelik olarak yeniden şekillendirecektir (Gülen, 2005). Böylece KÖO modelinde kamu değeri kamunun gözetiminde özel firmalar yoluyla üretilebilecektir.

\subsection{Kamu Değeri Temelli Performans Sistemi}

KÖO modellerinde yukarıda açıklanan türde bir stratejik ilişkinin kurulması büyük ölçüde bu ilişkiyi destekleyecek performans sistemine bağlı olacaktır. Bu bağlamda önerilecek performans sisteminin kamu değeri temelli bir karakteristiğe sahip olması gerekecektir.

Kamunun ortaklık yapacağı bir firmayı değerlendirmek ve sonrasında yaptığı işleri puanlayabilmek için birçok nicel olmayan göstergeye ihtiyacı olacaktır. Bu yüzden bu performans sisteminde Kaplan ve Norton tarafindan geliştirilen Balanced Scorecard (BSC) modelinin özel bir uyarlama ile kullanılabileceği değerlendirilmektedir. Bu modelde Kaplan ve Norton şirketleri sadece finansal veriler ile değerlendirmenin yetersiz olduğunu görerek ölçütleri daha dengeli bir şekilde belirleme yoluna gitmişlerdir. Bu ölçütleri ise dört ana perspektif altında toplamışlardır: Finansal Nitelikler, Müşteri Tatmini, İç Süreçler, İnovasyon ve Gelişim (Kaplan ve Norton, 1996:5). BSC modeli uzun vadeli strateji belirlemek isteyen şirketler için sadece geçmişin verilerini değil geleceğin çeşitli değerlerini de hesaba katan bir performans sistemi olarak göze çarpmaktadır. Bu özelliği ile kamu değeri olarak nitelendirilen değerlere yönelik ve uzun vadeli bir ilişki türünü destekleyecek şekilde bir performans sistemi için uygun özelliklere sahiptir. Kamu değeri yaklaşımının kurucusu olan Moore'da performans ölçümü için Scorecard uygulamasının çok uygun olduğunu görerek "Public Value Scorecard” ölçüm metodolojisini ortaya atmıştır (Moore, 2003).

Ancak BSC modeli önerilen performans sistemi için sadece bir zemin oluşturacaktır. BSC modelinin bu sisteme katkısı özellikle nitel verilerin nicel verilere dönüştürülmesi yönünde olacaktır. Çünkü performans sisteminde firmaların çeşitli kriterlere ait puanları olacak ve puanlarla değerlendirilecektir. Bu puanlar ise KPI olarak adlandırılan anahtar göstergelerden sağlanacaktır (Kaplan ve Norton, 1996). ${ }^{1}$ Firmalar aldıkları puanlar ölçüsünde kamuyla iş yapma olanağına sahip olacaktır. Bu yüzden uzun vadeli işbirliği için firmaların performans sistemine yönelik bir strateji geliştirmeleri gerekecektir. Performans sisteminin kamu değerini ölçüt olarak alması özel sektör firmalarının da bu yönde değişim geçirmesine olanak sağlayacaktır.

KÖO’lar için geliştirilecek performans sisteminde iki boyut bulunacaktır. Birinci boyut tüm firmalar için objektif ve genel kriterler belirleyen ve kamuyla iş yapacak firmalarda bulunması gereken özellikleri tanımlayacak bir yapıya sahip olacaktır. Bu boyutta değer temelli bir takım göstergelerle birlikte firmanın kamu değeri üretme kapasitesi belirlenmeye çalışılacaktır. Bu amaçla iş güvenliği, çevre, iş standartları, kalite politikası, misyon ve vizyonu, bitirdiği işlere ait

\footnotetext{
${ }^{1}$ KPI İngilizce Key Point Indicators sözcüklerinin kısaltılmış hali. Türkçe’ye anahtar göstergeler olarak çevrilmiştir.
} 
değerlendirmeler (zamanında teslim, şartnameye uyum, kalite vb.) birer gösterge olacak ve firmaya puan sağlayacaktır.

Performans sisteminin ikinci boyutu ise yapılan işlere göre değişkenlik gösterecek olan kamu değeri göstergeleridir. Bu boyutta ortaklık yapılan firma üretilen kamu değeri bağlamında değerlendirilecektir. Bu amaçla firmaların yeni bir işe başlaması durumunda bu işe ait kamu değeri göstergeleri de belirlenecektir. Her bir işe ait tam puan önceden sabit olarak belirlenecektir. Örnek vermek gerekirse bir firmanın yapılan işten kamu değeri ölçütlerine göre alması gereken tam puan 100 olarak belirlenebilir. Bu durumda puan sabit kalır ancak puanı oluşturan göstergeler ve bunların ağırlıkları değişkenlik gösterir. Firmalar farklı işlerde farklı kamu değeri göstergelerine göre puanlar alır. Ancak tam puan sabit kalacağı için ölçme ve değerlendirme daha rasyonel bir şekilde sağlanabilir ve firmalar puan bazında birbirleriyle karşılaştırabilir.

Kamu değeri performans puanın hesaplanması ile birlikte çeşitli yöntemlerle bu puanın kullanılması mümkün olabilecektir. Buna uygun iki örnek vermek gerekirse: Ortaklık kurulacak bir iş için kamu değeri taban puanı belirlenebilir. Sadece bu puanın üstünde olan firmalar başvuruda bulunabilir. Hatta işin kapsam ve boyutuna göre artan oranlarda kamu değeri performans değerleri belirlenebilir. İkinci örnekte ihale usulü yapılan tekliflerde kamu değeri performans puanı da hesaba katılır. Kamu değeri puanı/ teklif bedeli gibi bir oran ile firma seçimi yapılır. Veyahut aynı teklifi veren iki firma arasında seçim kamu değeri performans puanı yüksek olan lehine kullanılır. Netice olarak kamu değeri performans değerinin belirlenmesi sonucu firmaların iş alma ve yapma süreçlerine bu puan etki edecek şekilde çeşitli düzenlemeler getirilebilir.

Yapılacak işlerin şartnamelerinde de kamu değeri göstergelerinin belirlenmesi gerekecektir. Böylece işi üstlenen firma çalışmaya başlamadan hangi ölçütlere dikkat edeceğini bilecektir. Bir yandan işi bitirip kâr elde edebilmek için planlı çalışmalarını yürütecek, bir yandan da stratejik işbirliğini sürdürmek ve daha büyük işlere katılabilmek için kamu değeri göstergelerinin karşılanmasını sağlayacaktır. Firmalar hem kamu değeri temelli bir strateji geliştirebilecek hem de bu stratejiyi kârlı bir çalışmayla sürdürebilecektir.

Özetle burada önerilen performans sistemi ile özel sektör firmaları kamu ile uzun vadeli bir işbirliği için teşvik edilecektir. Stratejik ortaklık dediğimiz bu işbirliği ile firmaların performans sisteminden aldıkları puanlar kamuya iş yapma olanaklarını etkileyecektir. Performans sistemi kamu değeri temelli ölçütleri içerdiği için firmaları bu değerleri artıracak işlemlere ve yapısal değişikliklere yönlendirecektir. $\mathrm{Bu}$ sayede KÖO modellerinde kamu değeri temelli bir uygulama hayata geçirilebilecektir.

\section{SONUÇ}

Kamu değeri yönetimi günümüzün gelişen çok aktörlü, ăg ilişkilerinin öne çıktığ y yönetim modellerine uygunluğu ile göze çarpsa da uygulama zorlukları nedeniyle ancak pilot çalışmalar seviyesinde kalabilmiştir. Kamu özel ortaklıkları ise YKİ reformları ile yıldızı parlayan ancak gerek yasal olarak gerekse de uygulama olarak çeşitli problemlerin tam giderilemediği bir model görünümündedir. Bu yüzden bu iki yönetim modelinin örtüştürülmesi her iki kavrama da katma değer sağlayabilecek bir nitelik taşıyabilecektir. Hem bu alanda fazla çalışmanın yapılmamış olması, hem de KDY kavramına teorik girdi sağlayabilmek amacıyla KÖO modeli bazında bir uygulama yöntemi geliştirilmesi hedeflenmiştir.

Kamu tarafında KDY dönüşümünün sağlanabilmesi, uygulama alanının çok geniş olmaması nedeniyle erişilebilir bir hedef olarak değerlendirilmektedir. Netice itibarıla daha önce de pilot çalışmalar yapılmış ve bu çalışmalardan çeşitli kazanımlar elde edilmiştir. Bu çalışmadaki öneride sadece fizibiliteyi yapan ve koordinasyonu uygulayan birimlerde böyle bir dönüşüm gerekmektedir. Yani uygulama kapsamı daha önce yapılan ve başarılı sonuçlar elde edilen pilot çalışmaların 
kapsamına benzer olacaktır. Bu sebeple kamu tarafinda bu kapsamda bir uygulamada herhangi bir problem görünmemektedir. Kritik olan nokta ilgili personelin doğru şekilde eğitilmesi ve bu personelin modele uygun şekilde hareket etmeleridir. Böylece kamu tarafinda KDY'ye yönelik bahsedilen kapsamda bir uygulamanın gerçekleşebileceği değerlendirilmektedir.

Bir diğer önemli konu olan özel sektörün bu ortaklığa razı edilmesi için iki tür öneriye yer verilmiştir. Bunlar kamu değeri temelli bir performans sistemi ve özel sektör ve kamu sektörü arasında kurulacak yeni ilişki türünü içermektedir. Bu ilişkiye çalışmada stratejik ortaklık adı verilmiştir. $\mathrm{Bu}$ her iki önerinin de benzer kavram ve uygulamalarla karşılaştırılması sonucu uygulanabilir olduğu değerlendirilmektedir. Bunlardan kamu değeri temelli performans sistemi Kaplan ve Norton tarafından geliştirilen BSC modelini temel almaktadır. BSC modeli ortaya atıldığ1 zamandan beri sürekli gelişim göstermiş, kurumsal firmaların nicel olmayan verilerini ölçebilmek amacıyla sıklıkla başvurulan bir yöntem haline gelmiştir. Yıllardır kullanılan BSC modeli yapılacak uyarlamalar ile kamu değeri temelli göstergeleri ölçmek için adapte edilecektir. Özel sektördeki benzer uygulamalar bu modelin performans ölçümü için uyarlanabilir olduğunu göstermektedir. Bu durumda önem kazanan husus belirlenecek kamu değeri göstergeleri olmaktadır. Çünkü her bir ortaklık çeşidinde, farklı kamu değeri göstergeleri ortaya çıkacaktır.

Önerilen yöntem bağlamında belki de en önemli nokta özel sektörün KDY bazlı bir sisteme motive edilmesidir. Bunun sağlanabilmesi için bu çalışmada önerilen yeni ilişki türü, stratejik ortaklık, özel sektörde benzerini bulabileceğimiz bir modeldir. Özellikle otomotiv sanayinde yıllardır kullanılan yalın tedarik zinciri ile çeşitli açılardan benzerlikler taşımaktadır. Bu ilişki türünde firmalar daha kısa vadeli kazançlar yerine uzun vadeli ve her iki tarafın da kazanabileceği bir birlikteliği benimsemektedirler. Otomotiv sanayinde yoğun olarak kullanılan bu ilişki modeli de yıllardır başarıyla uygulanmaktadır. Bu sebeple kamu ve özel sektör arasında kurulacak ve stratejik ortaklık adını verdiğimiz modelin de benzer örneklerinde olduğu gibi mümkün olacağı değerlendirilmektedir.

Sonuç olarak bu çalışmada Kamu Değeri Yönetimi ile kamu-özel ortaklıkları modeli üzerine bir uygulama yöntemi öneri olarak ortaya atılmış ve çeşitli yönleriyle tartışılmıştır. Bu yöntem özel sektörde benzerleri bulunan ve başarılı şekilde uygulanan başka yöntemlerden istifade edilerek oluşturulmuştur. $\mathrm{Bu}$ sebeple açıklanan yöntemin uygulanabilir bir nitelikte olduğu değerlendirilmektedir. Böylece Kamu Değeri Yönetimi için yeni bir alanda uygulamanın mümkün olabileceği ve uygulanması durumunda kamu değeri üretmede etkin bir yöntem olabileceği gösterilmeye çalışılmıştır.

\section{KAYNAKÇA}

Benington, J. \& Moore, M. H. (2011). Public Value: Theory and Practice (1. Edition). Palgrave Macmillan.

Brandenburger, A. M. \& Stuart Jr, H. W. (1996). Value-Based Business Strategy. Journal of Economics \& Management Strategy, 5(1), 5-24.

Devos, G. \& Bouckenooghe, D. (2006). Individual and Organisational Facets of Change in The Public and Private Sectors: A Comparative Study. Asia Pacific Journal of Public Administration, 28(2), 201-229.

Gülen, K. G. (2005). Lojistik Hizmetlerde Dış Kaynak Kullanımının Yaygınlaşması ve Tedarikçi İşletmelerde Gelişim Stratejileri, İstanbul Ticaret Üniversitesi Fen Bilimleri Dergisi, 4(8), 2948.

Güzelsari, S. (2009). Kamu Özel Ortaklıkları Üzerine Eleştirel Bir Değerlendirme, Kamu Yönetimi: Yapı İşleyiş Reform, Ankara Üniversitesi Siyasal Bilgiler Fakültesi Yayınları, Yayın No: 598, Ankara.

Horner L., Rebecca F. \& Michelle M. (2007). Creating Public Value: Case Studies. The Work Foundation, London. 
Horner, L. \& Hutton, W. (2011). Public Value, Deliberative Democracy and the Role of Public Managers, Public Value Theory and Practice, Book Chapter, Ed. John Benington \& Mark Moore. Palgrave Macmillan.

Kaplan, R. S. \& Norton, D. P. (1996). Putting the Balanced Scorecard to Work, Harvard Business Review, January-February, s.1-18.

Karkın, N. (2012). Kamu Siyasalarının Üretilmesinde Yeni Bir Ölçüt: Kamusal Değer Kavramı ve Kritiği, Kamu Politikalarında Dönüşüm- Kayfor2012 Bildiriler Kitabı, TODAİE Yayınları, Ankara, s.359-372.

Kelly, G., Mulgan G. \& Muers S. (2002). Creating Public Value- An Analytical Framework for Public Service Reform. Londra. Strategy Unit, Cabinet Office.

Kivleniece I, Kivleniece B.Q. (2012). Creating and Capturing Value in Public-Private Ties: A Private Actor's Perspective, Academy of Management Review, 37(2), 272-299.

Köseoğlu Ö. \& Sobacı Z. (2014). Kamu Politikaları Yoluyla Kamu Değeri Üretmek, Kamu Yönetiminde Değişim- Kayfor12 Bildiriler Kitabı, TOBB \& Adnan Menderes Üniversitesi, s. 434-450.

Köseoğlu Ö. \& Tuncer A. (2014). Kamu Yönetiminde Yeni Bir Yaklaşım Olarak Kamu Değeri: Kavramsal ve Kuramsal Açıdan Bir Tartışma, Yönetim Bilimleri Dergisi, 12(24), 145-170.

Liker, J. K. (2004). The Toyota Way (1. Edition). McGraw-Hill Professional.

Martin, J. D. \& Petty, J. W. (2001). Value Based Management: The Corporate Response to The Shareholder Revolution. Oxford University Press.

Moore M. H. (2005). Creating Public Value Through Private/Public Partnerships, CLAD X Santiago Kongre Bildirileri, Şili.

Moore, M. H. (1995). Creating Public Value: Strategic Management in Government. London. Harvard University Press.

Moore, M. H. (2003). The Public Value Scorecard: A Rejoinder and An Alternative To 'Strategic Performance Measurement and Management in Non-Profit Organizations' by Robert Kaplan. Hauser Center For Nonprofit Organizations Working Paper, (18).

O'flynn, J. (2007). From New Public Management to Public Value: Paradigmatic Change and Managerial Implications, The Australian Journal of Public Administration, 66(3), 353-366.

Reynaers, A. M. (2010). Public Values and Integrity in Public-Private Partnerships, EGPA Kongre Bildirileri, Study Group on Ethics and Integrity of Governance, Toulouse, Eylül 8-10.

Rivera, L., Chen, F. F., \& Lee, W. M. (2007). Beyond Partnerships: The Power of Lean Supply Chains. In Trends in Supply Chain Design and Management, Springer Yayınları, Londra, s.241268.

Stoker, G. (2006). Public Value Management A New Narrative for Networked Governance?, American Review of Public Administration, 36(1), 41-57.

Uz, A. (2007). Kamu-Özel Ortaklığı/Public-Private Partnershıp (PPP) (Kavram ve Hukuksal Çerçeve), Gazi Üniversitesi Hukuk Fakültesi Dergisi, XI(1-2), 1165-1182.

Williams, I. \& Shearer, H. (2011). Appraising Public Value: Past, Present And Futures, Public Administration, 89(4), 1367-1384.

Yang, K. (2016). Creating Public Value and Institutional Innovations Across Boundaries: An Integrative Process of Participation, Legitimation, And Implementation, Public Administration Review, 76(6), 873-885. 